\title{
Human-Machine-Cooperation Design Methodology for Civil Aircraft Cockpit
}

\author{
Zhili Tang \\ School of Electronics and Information \\ Northwestern Polytechnical University \\ Xi'an, China \\ e-mail:zltang@nwpu.edu.cn
}

\author{
An Zhang \\ School of Electronics and Information \\ Northwestern Polytechnical University \\ Xi'an, China \\ e-mail: zhangan@nwpu.edu.cn
}

\begin{abstract}
As far as the safety of civil aviation is concerned, the relationship between pilots and automation systems is always the focus of cockpit design discussed by system designers. Based on the famous "Crew Centered" design philosophy, the human-machine-cooperation design methodology of civil aircraft cockpit is introduced, which contain human-machine function allocation, human-machine interface simulation and evaluation. The result of function allocation has a direct influence on human-machine interface because it determines the material format of interface. Furthermore, humanmachine interface simulation and evaluation can validate the work efficiency of function allocation. So the cockpit interface designed by human-machine-cooperation design methodology will veritably realize the combination of human and machine, which can enormously enhance the safety and effectively of the civil aircraft cockpit.
\end{abstract}

Keywords-Human-machine-cooperation, Function allocation, Interface simulation, Interface evaluation

\section{INTRODUCTION}

Civil aviation transportation is developing faster and faster in the whole world and the safety, effectiveness and economy of the plane are being paid more and more attention. The fast developing market brings new challenges for civil aviation technology. Advanced automation systems, new materials, new air traffic control system, and so on, are under study or being tested for application. As far as we can see, an evolution of the civil aviation technology is almost coming up. Among all the researches on new civil aviation theory and technology, those on the aircraft cockpit play an important role in enhancing the performance of the humanmachine system onboard the aircraft, especially the safety of the flight.

Aircraft cockpit is the main workplace for pilots in flight. Pilots receive flight information by visually searching outside the cockpit and reading the display inside, then control the aircraft with different controllers in the cockpit. The cockpit is the center of an aircraft and it's so important that the safety and effectiveness of the flight are tightly linked with it. Ever since the flight of the world's first plane, the cockpit of civil aircraft has developed enormously. It goes through 5 main development phases. With the rapid evolution of automatic and electric technology, several new development trends of future cockpits are presented:

\section{A. High definition large screen panoramic display/control system}

For the comprehensive awareness of the aircraft's situation, large size display is necessary. Touch and voice could be control means.

\section{B. $3 D$ and $4 D$ display mode}

3D and 4D graphical information can help pilots get stronger situation awareness ability, react faster, and avoid errors [1][2].

\section{The use of HUD}

The Head-up Display (HUD) has been applied on military aircrafts, especially fighters, for 40 years and shown great effect. It can help pilots reduce the workload and avoid attention distraction in crucial flight phases, such as taking off, approaching and landing.

\section{Cockpit automation}

In modern civil aircraft's cockpit, automation system has been widely used. Along with its function to reduce pilots' workload, automatic system also brings the threat of air crash due to pilots' relaxing or the failure in the interaction between it and pilots [3]. The problem of how to allocate and manage the tasks of pilots and the automatic systems is more and more crucial.

\section{The Design Methodology of Civil Aircraft COCKPIT}

Along with the benefit of technology developments in the cockpit, especially the application of auto-pilot, two problems turned out crucial in today's cockpit design:

1) How to allocate and manage the tasks of human and the automatic system, defined as Human-machine Function Allocation (HMFA) problem.

2) The Human-machine Interface (HMI) problem, more specifically, the HMI design and evaluation problem.

Both function allocation and interface design and evaluation are typical problems from human-machine system. In a human-machine system, function allocation and interface design are tightly linked with each other. The interface design must take the function allocation scheme into consideration. They are the two major parts of a humanmachine system design process. 
With the application of more and more advanced automatic systems, the relationship between the machine and pilots has become more complex. To deal with this relationship, designers need a philosophy to guide their work. "Crew Centered" [4] is a design philosophy accepted by most cockpit designers. But different civil aircraft manufacturing companies take different design strategies. Boeing and Airbus, two magnates in civil aircraft manufacturing, held different strategies in the design of their typical aircrafts' cockpits [5][6][7][8]. The "human dominant” strategy, taken by Boeing, means that pilots hold

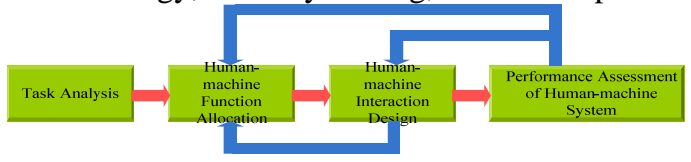

Figure 1. Flow chat of HMCDM

the final decision-making authority and the machine should provide enough information for pilots. Boeing's understanding of "Crew Centered" emphasizes human's subjective activity, while Airbus emphasizes the inevitability of human-errors instead. The "machine dominant" strategy, taken by Airbus, means that the automation system takes as many tasks as possible. Both "Human dominant" and "Machine dominant" have inner problems, which have caused serious accidents. So we bring forward the Humanmachine-cooperation Design Methodology (HMCDM), which get man and automation system finish respective adept tasks and cooperate with each other. Human and the machine are colleagues. With this philosophy, the design of the cockpit will be carried out in the process with four main steps, as shown in Fig. 1.

\section{HMFA OF CIVIL AIRCRAFT COCKPIT}

\section{A. HMFA process of civil cockpit}

HMFA concept is a part of Function Allocation (FA). The concept of FA was firstly presented by P. M. Fitts in 1951 [9]. FA is a process in which functions or tasks in systems are allocated to man or machines. Currently, FA is widely applied in automatic monitor systems in nuclear power plant, control systems of the UCAV, control systems of manned space flight, air traffic control, the design of pilot's cockpit, etc. HMFA of civil cockpit means that functions in civil cockpit are properly allocated to pilots or cockpit systems. Fig. 2 is the flow chat of HMFA for civil cockpit.

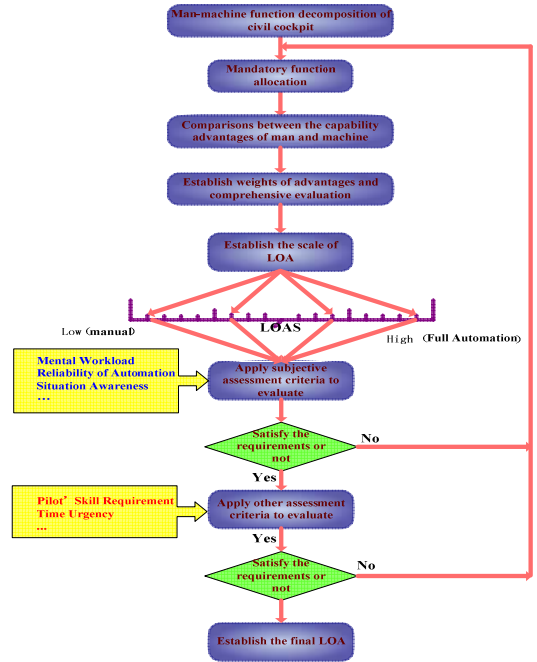

Figure 2. Flow chat of HMFA

TABLE I. AUTOMATION LEVEL

\begin{tabular}{|c|c|}
\hline LOAs & Description \\
\hline 1 & $\begin{array}{l}\text { System does not provide any assistance, one must } \\
\text { complete all the decisions and manipulation }\end{array}$ \\
\hline 2 & System provides decision-making or action plan \\
\hline 3 & System narrows scheme selection \\
\hline 4 & System provides a proposal \\
\hline 5 & Execute the plan if humans agree \\
\hline 6 & $\begin{array}{l}\text { The scheme is allowed to be vetoed in the limited time } \\
\text { before the implementation }\end{array}$ \\
\hline 7 & $\begin{array}{l}\text { Implement Automatically unless it is necessary to notice } \\
\text { human being }\end{array}$ \\
\hline 8 & Told them if humans want to know \\
\hline 9 & Whether or not to inform humans is decided by computer \\
\hline 10 & $\begin{array}{l}\text { System decides all the work and refuses to man's } \\
\text { intervention }\end{array}$ \\
\hline
\end{tabular}

B. The automation level of FA in human-machine systems

In the process of function allocation in human-machine systems, through the allocation function between man and machine, it can be argued that man and machine are a cooperative relationship. The relationship represents in the different Levels of Automation (LOAs) of human-machine functions. Currently, there are a variety of divisions about LOAs of human-machine interaction systems [10] [11]. Sheridan, Verplank and Parasuraman have put forward a method about automation level of human-machine interaction systems, as shown in Tab. I. Nowadays, many other schemes are just based on some certain merged or refined level.

\section{The method of HMFA based on the ULMADM}

Here, FA can be regarded as a multiple attribute decision making (MADM) problem [12]. In order to solve the highly 
uncertain decision problems in the early stages of design, we introduce a kind of the ULMADM (Uncertain Linguistic Multiple Attribute Decision Making) method and use UEWAA (Uncertain Extended Weighted Arithmetic Averaging) and ULHA (Uncertain Linguistic Hybrid Aggregation) operators to solve these problems in humanmachine systems [13][14].

1) Confirm the automation level range of function allocation: The automation level range can be determined according to a comprehensive comparison about each of capability advantages of man and machine. The method about how to determine the automation level range is based on UEWAA operator.

2) Determine the automation level of function allocation: Automation level range of function allocation has been established, namely, several different solutions to function allocation are given. However, selecting the optimal scheme from the solutions is still needed according to function allocation evaluation criteria. Eventually, the final automation level of human-machine function allocation can be determined. In the practical evaluation process, in order to reduce experts' subjective deviation, different schemes are usually graded by several evaluation experts in accordance with the evaluation criteria. The MADM method based on UEWAA and ULHA operators is used to determine the automation level of function allocation.

According to the method mentioned above, we take takeoff, landing, fault diagnosis and avoidance system as examples of FA, after the calculation, the results demonstrate that the proposed method about function allocation is feasible and effective.

\section{HMI SIMULATION FOR CIVIL AIRCRAFT COCKPIT}

We have built a simulation system based on VMIC (Virtual Memory Image Card) optical fiber network, which is comprised of cockpit display/control simulator, flight visual simulator, and synthetic evaluation software, as shown in Fig. 3. With this system, we can test the human-machine function allocation scheme and the interface design in different kinds of flight situation and multi tasks, as shown in Fig. 4 and Fig. 5.

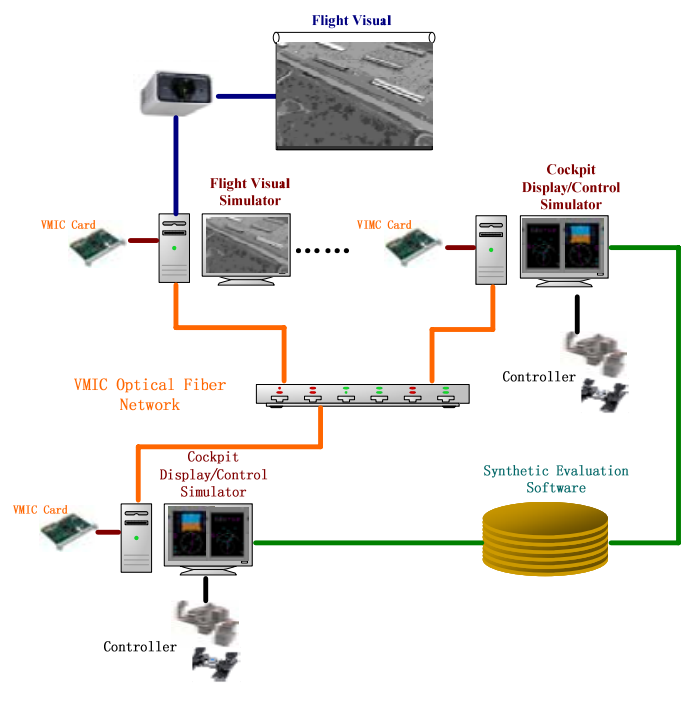

Figure 3. Configuration of civil aircraft cockpit simulation

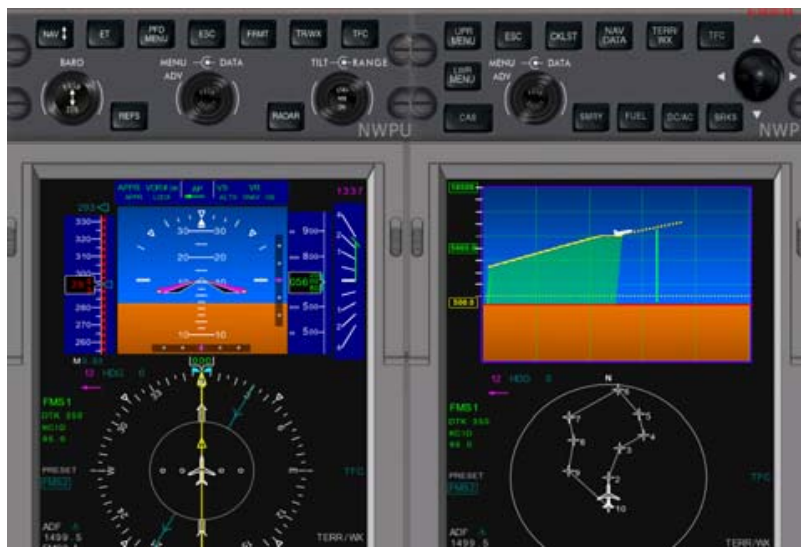

Figure 4. Simulation interface of PFD

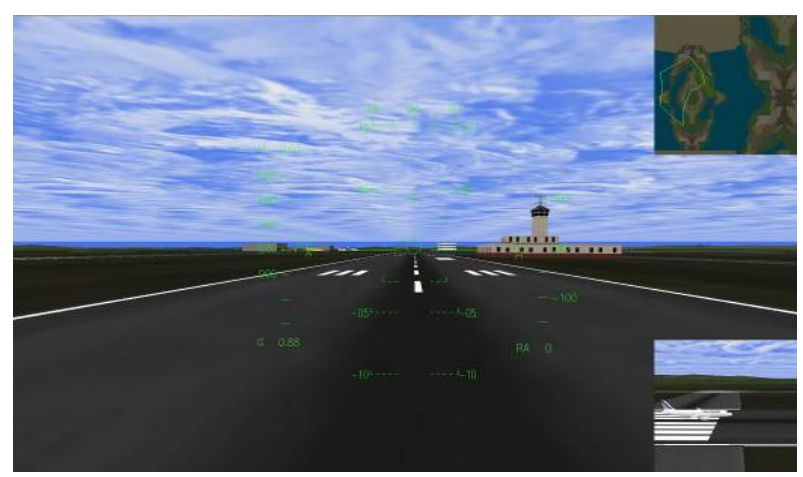

Figure 5. Simulation interface of scene outward cockpit 


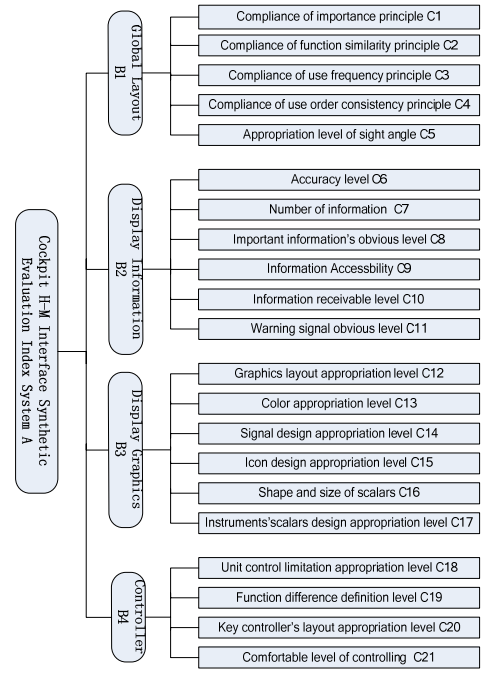

Figure 6. Synthetic evaluation index system for cockpit

\section{HMI SynthetiC EVALUATION FOR CiVIL AIRCRAFT COCKPIT}

Taking into account the characteristics of civil aircraft HMI, numbers of HMI evaluation methods have been compared with each other and the key technologies for synthetic evaluation were identified. The index system should be scientific, objective, complete, sensitive, comparable, operable, and consistent with the evaluation method. Our index system was built up based on the adequate analysis of displays and controllers, as shown in Fig. 6.

The weight is an important factor in the HMI synthetic evaluation index system because it reflects valuator's cognition of important degree to the single index. The final result of evaluation will change with the modification of every weight. And how to avoid the bias of valuator's is also a challenge for us to determine the weight. Generally, methods to determine weights can be divided into three categories: (1) subjective weighting, (2) Objective weighting, (3) Combination weighting. The last method combines the advantages of subjective weighting and objective weighting, so it was adopted in our research.

TABLE II. Evaluation Results of Three Methods

\begin{tabular}{|c|c|}
\hline Method & Result \\
\hline AHP & 82.6949 (Fine) \\
\hline SPA & 4.2403 Level (Fine) \\
\hline BPN & 83.92 (Fine) \\
\hline $\begin{array}{c}\text { Average value of numbers of } \\
\text { experiments }\end{array}$ & 84.63 (Fine) \\
\hline
\end{tabular}

Several synthesis methods were taken in our research: (1) Advanced Analytic Hierarchy Process (AHP) [15], (2) Set Pair Analysis (SPA) [16], (3) BP Network (BPN). All three synthesis methods were taken to evaluation the simulation system of certain civil aircraft cockpit. Consistent results were gotten in the three methods, as shown in Tab. II. From the result we can find that of SPA is suitable to evaluate the rough grad, while the other two methods can get more accurately value.

\section{CONCLUSIONS}

In this paper, a methodology of cockpit design for civil aircraft has been put forward. It includes three pivotal stages. The first is HMFA that decide which and when a function should be allocated to man or machine by ULMADM method. Then we put the result of HMFA into application through VMIC simulation platform. Finally, on the base of a synthetic evaluation index system, three synthesis methods were given to validate the design efficiency. The theoretical analysis and simulation results show that HMCDM is reasonable and effective. In conclusion, the model could provide a profound theoretical value for practical applications. The current model, through proper modifications after more experimentation, will apply to certain civil aircraft design project. We also believe HMCDM is consequentially helpful for future researches on civil aircraft cockpit.

\section{ACKNOWLEDGMENT}

This work was funded by National Basic Research Program of China (973 Program: 2010CB734104).

\section{REFERENCES}

[1] G. F. Ardey. "Fusion and display of data according to the design experimentation philosophy of intuitive use,” NASA no.19990092816, 1999.

[2] R. A. Faerber, and T. J. Etherington. "Advanced flight deck for next generation aircraft," Piscataway NJ, Proceedings of DASCAIAA/IEEE/SAE Digital Avionics Systems Conference,vol. 1, 1998, pp. E42-1-E42-8.

[3] N. J. Mahwah. "Automation and human performance: Theory and applications,” Lawrence Erlbaum Associates, 1996, pp. 117-136.

[4] T P Michael. "Summary of a crew-centered flight deck design philosophy for high-speed civil transport (HSCT) aircraft," NASA Langley Research Center, 2001.

[5] W. Xu. "Psychological study on the interaction of human and machine system in the automatic aircraft cockpit," in Psychology Science, vol. 26 ,September 2003, pp. 523-524.

[6] 767-36D user handbook, Shanghai Airline, 2011.

[7] 737-700/-800 Crew user handbook, Shanghai Airline, 2010.

[8] A321 Crew user handbook, Shanghai Airline, 2009.

[9] P. Fitts. "Human engineering for an effective air-navigation and traffic-control system," Washington: National Research Council Division of Anthropology and Psychology Committee on Aviation Psychology, 1951.

[10] R. Parasuraman, T. B. Sheriden, and C. D. Wickens. "A Model for Types and Levels of Human Interaction with Automation," IEEE Transactions on Systems, Man, and Cybernetics-Part A: Systems and Humans,vol. 30, March 2000, pp. 286-297.

[11] M. R. Endsley, and D. B. Kaber. "Level of automation effects on performance, Situation awareness and workload in a dynamic control task,” in Ergonomics, vol. 42, May 1999, pp. 462-492.

[12] A. Zhang, Z. L. Tang, and C. Chao, "Man-machine function allocation based on uncertain linguistic multiple attribute decision making," in Chinese Journal of Aeronautics, vol. 24, December 2011, pp. 816-822. 
[13] T. L. Saaty. "The analytic hierarchy process: planning, priority setting,” New York: Mcgraw-Hill, 1998.

[14] Z. S. Xu. “An Overview of methods for determining OWA weight," in International Journal of intelligent Systems, vol. 20, June 2005, pp. 843-865.
[15] J. S. Finan, and W. J. Hurley, "Transitive calibration of the AHP verbal scale,” in European Journal of Operational Research, vol. 112, February 1999, pp. 367-372.

[16] Y. C. Ye, L. H. Ke, D. and Y. Huang, "Application and technique of system synthetic evaluation,” Beijing: Metallurgy Industry Press, 2006. 